\title{
EDITORIAL
}

\section{FORENSIC PRACTICE IN SRI LANKA: PRESENT AND FUTURE}

\author{
Vadysinghe A.N. \\ Department of Forensic Medicine, Faculty of Medicine, University of Peradeniya, \\ Sri Lanka \\ E-mail: amal_vadysinghe@yahoo.com \\ (iD) https: / / orcid.org/0000-0002-1994-7830
}

Sri Lanka is a small island located in the Indian Ocean. It is divided into nine provinces and twenty five districts for administrative purposes including medico-legal services. Local medical faculties produce medical professionals for the needs of the country with a fraction coming from recognized foreign medical faculties.

Successful completion of the forensic medicine component of the undergraduate program or successful completion of a separate examination which includes a forensic medicine component for foreign qualified medical graduates is required to practice medicine in Sri Lanka. This is regulated by the University Grants Commission and the Sri Lanka Medical Council. This mechanism ensures competent medico-legal management from the initial stages of healthcare provision.

There is a medico-legal unit or division in all government hospitals and departments of forensic medicine in all medical faculties of Sri Lankan universities. Most medicolegal units are manned by board certified specialists in forensic medicine or in the case of smaller hospitals Medical Officers with special training in forensic medicine further strengthening the medicolegal services within the country.

Postgraduate specialization or a doctorate in forensic medicine (MD) is awarded by the Postgraduate Institute of Medicine, University of Colombo to maintain the highest standards. Mandatory training in recognized forensic units locally and abroad, with evaluations conducted by eminent forensic specialists in other countries ensure training on par with internationally accepted training centres.

All articles in Sri Lanka Journal of Forensic Medicine, Science \& Law are licensed under the terms of the Creative Commons Attribution-Non Commercial 4.0 International License. 
Till recently board certified specialists managed all cases in the fields of clinical forensic medicine, forensic pathology, anthropology, toxicology, paediatric pathology radiology and etc. However, the recently revised postgraduate curriculum incorporated subspecialty training in above mentioned areas after completion of the MD.

Once a candidate selects a subspecialty he is expected to complete a research project in that particular area while obtaining further training in a recognized oversees unit in the field for a minimum period of six months.

It is expected that once those who are so trained assume duties as forensic specialists with special interest in a specific subspecialty that they will provide expertise in the field of subspecialisation in addition to the routine medico-legal work. These forensic specialist are placed in main forensic units to cover the work of the entire country to uplift the forensic services in Sri Lanka. It is expected that when adequate numbers of specialists with special interests are produced, further subspecialties of forensic medicine would be offered by the PGIM (eg. forensic histopathologist, forensic neuropathologist, forensic radiologist, forensic paediatric pathologist etc) .
In conjunction with these changes, the existing Diploma in Forensic Medicine (DLM) has been upgraded to a Master in Forensic Medicine subsequent to strengthening the research component. The course leading to a masters is aimed at medical graduates who are in forensic practice or in medical administration.

This uplifting of the Forensic Medicine postgraduate program in Sri Lanka to a doctorate in Forensic Medicine with special interest areas or subspecialties and a Master programme with a research component brings the postgraduate forensic medicine training on Sri Lanka in par with international standards.

This enhancement of the postgraduate Forensic Medicine training program may influence the undergraduate Forensic Medicine curriculum as the need for newly graduated doctors to attend to medico legal work would be less. Therefore credits allocation to the Forensic Medicine component of the undergraduate medical program may be reduced in future undergraduate medical curricular similar to Europe or North American systems. It is imperative that infrastructural development including buildings, technical and laboratory facilities of forensic units island wide need to occur to overcome future challenges. 